\title{
STATISTICS EDUCATION IN A POST-TRUTH ERA
}

\author{
Jim Ridgway*, James Nicholson*, and David Stern** \\ *School of Education, University of Durham, UK \\ ** Statistical Services Centre, University of Reading, UK \\ jim.ridgway@durham.ac.uk
}

Post-truth refers to a climate where emotional reactions and personal beliefs are used more in shaping opinion and forming the basis for political action than is empirical evidence. Contempt for evidence is socially corrosive. It violates the core values of the statistical community, and poses an existential threat to the idea of evidence-informed decision making. The task of developing resistance to post-truth should be shared amongst everyone involved in statistics education. Here, we explore some possible responses as a community; we need to promote a nonpartisan approach to promoting respect for high-quality evidence, and reasoning from evidence. We also need to look hard at our implicit acceptance of an 'evidence-informed' world view - when does the statistical and scientific community claim too much? After some scene setting (a brief introduction to the problem, and ideas on solutions from groups such as fact-checkers, social media platform providers, and journalists), we explore ways in which introductory statistics courses could be adapted to incorporate 'anti-post-truth' activities, then conclude with some ideas about how statistics educators can contribute to efforts from the broader community that depends on statistical literacy, and that is threatened by post-truth.

\section{POST-TRUTH}

"Post-truth" was chosen as 2016 "word of the year" by the Oxford Dictionaries. In a posttruth era, use of 'evidence' (veridical or not) is simply a rhetorical device to justify actions; other rhetorical devices such appeals to emotion, or to some mythical golden past are at least as valuable. As Helga Nowotny (2016) (a former president of the European Research Council) notes, using emotions as a guide to policy is a poor way to cope with uncertainty. Joachim Engel (2017) points to the paradox that post-truth has emerged at a time when high quality evidence to inform personal, social and political decisions has never been more abundant or accessible (see also Brook, 2010). 'Alternative-facts' and 'fake-news' and are associated with post-truth.

Alternative-facts is a synonym for 'lies'. United States President Trump (22 Jan 2017) claimed that more people attended his inauguration than President Obama's. His press secretary made statements to justify this claim, which were false. A senior Trump aide, when challenged about 'falsehoods' said that this was overly dramatic, and that they were merely 'alternative facts' (see video: channel4.com/news/alternative-facts-the-new-order-of-the-white-house). Fake-news has two distinct components. One is the invention of 'news stories' that are then circulated widely via social media. The second is illustrated by suppression of authoritative news and independent news agencies, and evidence from experts - illustrated by President Trump shouting the phrase 'fake news' at journalists during press conferences; excluding news agencies such as the BBC and the CNN from Presidential press conferences; and suppressing information about inter alia global warming.

\section{ON EVIDENCE-BASED DECISION MAKING}

Contempt for evidence can lead to some bad decisions, and is socially corrosive. It violates the core values of the statistical community. The task of developing resistance to posttruth is relevant to everyone involved in statistics education. However, we should look carefully at our own world-views. The mantra of 'evidence-based decision making' is naïve; decisions do not happen in a vacuum; evidence can be contested - it is not always robust or fit for purpose, and (at best) evidence can inform political decisions. Reasoning with high-quality evidence in public debate is not always done well - failure to explore disaggregated data in public policy is a particular weakness - focusing on aggregated data can lead citizens to feel that the evidence (e.g. at a national level, there has been little demographic change, and employment rates are high) bears no relation to their lived experience. We should also acknowledge that statistical and scientific communities sometimes claim to know more than they can know - exemplified by long-term economic forecasts 
for a post-Brexit UK, from OECD's chief economist. Over-claims by experts are dangerous because they can be used to justify a world view that rejects evidence and expertise in general.

The mantra of 'evidence-based decision making' is also being used by the development community. A problem which can occur is that 'experts' only accept evidence gathered from a single methodology, which provides a narrow perspective and often shifts the argument to a level of abstraction to which non-experts can no longer contribute. One example of this is the push towards randomised control trials (RCTs) for judging effectiveness. Some claim that this is the 'gold standard' for evidence of impact, and so other types of evidence are undervalued and dismissed. This can lead to a situation where 'experts' are seen as being out of touch with the realities on the ground, because of over-simpified views of causality, leading to further erosion of the general public's confidence in 'expert' opinion.

\section{POST-TRUTH: SUPPLY-SIDE PROBLEMS}

In the next two sections, we distinguish between supply-side and consumer-side problems, but are aware that the statistics education community can do little to address supply-side problems; our main thrust will to consider ways in which the statistics education community can empower students and citizens to resist the sirens of the post-truth era.

Examples of post-truth malpractice include:

- fake-news from unknown sources

- authoritative figures who invent evidence

- authoritative figures who suppress evidence

- authoritative figures who cherry-pick authentic information in order to mislead

Agents and agencies which can combat post-truth, include:

- politicians: can promote a climate of evidence-informed decision making

- media outlets: a number of outlets aim to create high quality, impartial news; agencies such as $\mathrm{CNN}$ and the BBC aim to produce impartial accounts - see Brooke, 2010

- fact-checkers: these are non-partisan organisiations that offer critical commentaries about data claims. Examples include Africa Check, chequeado, Full Fact and Politifact. There are interesting developments in the creation of tools that automate some aspects of fact-checking e.g. Factmata (bit.ly/2iUuNxu), and FACTS (bit.ly/2iVPz1H)

- regulatory bodies: some countries have agencies independent of government which are tasked with proving evidence and critical commentaries on misuse of data e.g. the UK Statistics Authority

- authoritative data sources: These include agencies such as OECD, Eurostat, the UN; national statistics offices, and data warehouses (e.g. data.gov and the CIA World Factbook); the ProCivicStat website is a modest example that provides links to data sets and to data visualisation tools

- non-partisan agencies that synthesise evidence: e.g. the Cochrane collaboration and the Alliance for Useful Evidence

- social activists: public demonstrations show outrage about public lies

- social media: social media have a vested interest in acting against fake news. However, if they are seen to be editing materials, they may be classified as 'publishers' and therefore subject to the laws that apply to publishers.

\section{POST-TRUTH: CONSUMER-SIDE PROBLEMS}

Examples of student and citizen vulnerabilities to post-truth malpractices include:

- Vulnerability to emotional appeals

- Lack of engagement

- Lack of criticality

- Inadequate skills in interpreting data.

We next describe ways in which statistics educators might respond. 


\section{Vulnerability to emotional appeals}

Statistics texts rarely present information in a form that is highly emotionally loaded; we suspect that this is also true of most statistics classes. The study of rhetoric goes back at least as far as Aristotle, but is neglected in many curriculum documents. One can argue that students should be asked to deconstruct arguments embedded in speeches and argumentative writing. Thouless (1930) offers advice and examples. Analyses of political statements that have been deconstructed by fact-checking organisations can be used to illustrate the interplay between rhetoric and data. The original claims, and fact-checkers' responses could be used to support teaching. The original claims can be deconstructed by students; some important statistical ideas appear in the responses from fact-checkers.

\section{Lack of engagement}

Students need to see that evidence can help make better decisions, and therefore that it is worth learning effective ways to analyse data. John Harraway (n.d.) has created videos illustrating the uses of statistics in a range of professional contexts. Stats and Stories is another excellent repository that can be used to support teaching.

Gal (2002) distinguishes between the knowledge elements of statistical literacy (literacy skill, statistical knowledge, mathematical knowledge, context knowledge and critical questions) and dispositional elements (beliefs and attitudes, critical stance). Dispositions cover a range of non-cognitive functions that include a sense of self-efficacy and empowerment. People who are comfortable with numbers, who feel that they can understand evidence-based arguments, and can reason about the information that is presented, are far more likely to engage with, and adopt a critical stance towards, arguments they come across in the media. People who are anxious about mathematics and statistics are less likely to engage. In a survey of sociology teachers who teach quantitative methods, Scott Jones \& Goldring (2014) report that over 90\% identified mathematics anxiety as the key barrier to learning. In a companion survey, $55 \%$ of undergraduate students identified mathematics anxiety as a barrier to working with data. Students need positive experiences reasoning with numbers. To this end, Scott Jones \& Goldring (2017) ask students to create sociological narratives around data that they explore. Statistics educators should find ways to build confidence in using numbers to make and deconstruct arguments.

\section{Developing criticality}

What we mean here by criticality is not simply being critical. There is a danger that a critical stance degenerates into cynicism about all sources of data ('lies, damn lies, and statistics'). Rather, criticality is about adopting the posture of a fair-minded skeptic willing to accept an account, but who needs to be persuaded by evidence. The idea that formal education should teach criticality is not new (e.g. Freire, 1972), nor is it a new idea in statistics education. For example, Watson (2006) describes a hierarchy of statistical literacy where the highest level requires students to demonstrate a critical questioning engagement that encompasses technique, nuances of language, and evidence in context.

There is a need to develop students' criticality as a 'habit of mind'. Elements include: actively looking for relevant evidence; questioning data provenance; questioning the motivation behind data collection; challenging the variables chosen and the ways they were operationalised; taking time to explore evidence, and telling stories that the data can and cannot support. Gal (2002) offers a list of 'worry questions' to be applied to statistical messages that exemplify criticality; they address issues such as: data provenance; samples and sampling; the reliability of the measures used; data presentation and interpretation; missing information; and alternative explanations. Internalising these questions is a good step on the way to developing appropriate of mind.

\section{Inadequate skills in interpreting data}

Much of the attention of politicians is devoted to policy on social issues. These topics are multivariate, and complex. Interpreting evidence related to social phenomena requires a range of skills not commonly found in introductory statistics curricula. Ridgway (2016), addressing the challenges the data revolution poses for statistics education, suggests radical changes in the statistics curriculum. These include paying more attention to: 
the politics of measurement - paying attention to the value systems implicit in the use of particular measures, and addressing ethical issues of access and ownership

measuring - constructing and critiquing measures (reliability, validity, use of composite indicators); properties of different summary statistics (e.g means vs medians), and of measures (e.g. absolute vs relative measures of poverty)

understanding how data are produced (and cleaned) and what different sorts of data gathering methods are good and bad for - so, paying attention to: study design (e.g. experiments are needed for causal inferences); sampling and bias (e.g. the dangers of convenience sampling); sample size and effect size; and to plausible generalization from particular data sets

understanding how different sources of data complement one another - in particular being able to search for coherent understanding from multiple data sources which might include quantitative and qualitative data at different grain sizes

data exploration - using the internet; finding and synthesizing data; data exploration - in particular via data visualisation

fitting data, explaining and predicting - in short, presenting statistics as a modelling activity (and understanding the promises and perils of modelling)

decision making and risk

the analysis of multivariate data (especially via interactive graphics) - addressing issues of association and causality, and the dangers of multiple comparisons

the use of mobile technologies - for data collection and to illustrate issues around data protection and privacy

formal and informal uses of words - students need to know that words used in statistics classes have technical meanings not necessarily shared with their everyday uses e.g. normal, random, regression, significant, confidence. The ProCivicStat project www.procivicstat.org offers a starting point, and links to relevant materials.

\section{COMMUNITY RESPONSES}

A number of disparate groups have vested interests in developing statistical literacy. These include data providers such as national statistics offices, organisations concerned with pubic wellbeing (e.g. in health), fact-checking organisations, professional associations, and some journalists, as well as statistics educators. There is scope for collaboration between these groups. Some examples follow:

- Fact-checking organisations often seek to educate both citizens and people making political claims, by highlighting common mistakes. There is scope for collaboration with academics on analyzing common errors, providing clear explanations of statistical principles, and developing defensive heuristics (see e.g. Ridgway et al, 2016; Arnold, 2017). These resources can be used in teaching

- Fact-checking organisations do want to develop criticality. The statistics education community could help by collaborating on 'worrying questions'

- Elections are often fought on the basis of claims and counter claims. Monitoring these claims can be an overwhelming task, even for fact-checking organisations. One response is for organisations to release staff with statistical skills to work for fact-checkers for a short time. For example, staff from the UK Office for National Statistics, and from IPSOS-Mori were released to work with Full Fact around the time of the 2015 general election (see Arnold, 2017). Statistics educators could support such initiatives both personally, and by encouraging student engagement

- Some agencies (e.g. The New York Times) have created materials for classroom use, specifically geared to addressing the issues of data provenance and data quality - statistics educators can use these materials, and could contribute to future developments

- Full Fact have developed a fact-checking toolkit - again, this could be used to support teaching.

These are discussed further in Ridgway (2017). 


\section{CONCLUSION}

Post-truth is a cultural phenomenon, and needs to be addressed as such. There is a need for groups who sees post-truth as a threat to the democratic process, to personal agency, and to responsible governance, to develop appropriate ways to respond in their own sphere of influence, and to find ways to collaborate with like-minded groups. There are strong arguments that statistics education should be reformed (e.g. Cobb, 2015). The threat that we will enter a post-truth era will make these calls even more strident. We make some suggestions about the ways that current curricula can be enhanced, and about ways that statistics educators can contribute to anti-post-truth actions.

\section{REFERENCES}

Africa Check (n.d.). https://africacheck.org/

Arnold, P. (2017). statistical literacy in public debate - examples from the UK 2015 general election. Statistics Education Research Journal, 16(1).

Brooke, H. (2010). The Revolution will be Digitised: Dispatches from the Information War. London: Heinemann.

Chequeado (n.d.). http://chequeado.com/

The CIA World Factbook https://www.cia.gov/library/publications/the-world-factbook/

Cobb, G. (2015) Mere Renovation is Too Little Too Late: We Need to Rethink our Undergraduate Curriculum from the Ground Up, The American Statistician, 69:4, 266-282.

Cochrane Collaboration (n.d.). http://uk.cochrane.org/

Culture Media and Sport Committee (2017). Inquiry into Fake News. https://www.parliament.uk/business/committees/committees-a-z/commons-select/culturemedia-and-sport-committee/inquiries/parliament-2015/inquiry2/

Engel, J. (2017). Statistical literacy for active citizenship: a call for data science education. Statistics Education Research Journal, 16(1).

Freire, P. (1972). Pedagogy of the Oppressed. London: Penguin.

Full Fact (n.d.). Full Fact's fact checking toolkit. https://fullfact.org/blog/2017/apr/factcheckingtoolkit-facebook-top-tips/

Gal, I. (2002). Adults' Statistical literacy: Meanings, components, responsibilities. International Statistical Review, 70(1), 1-25.

Harraway, L. (n.d.). ww.maths.otago.ac.nz/video/statistics/

New York Times (2015). https://learning.blogs.nytimes.com/2015/10/02/skills-and-strategies-fakenews-vs-real-news-determining-the-reliability-of-sources/

Nowotny, H. (2016). The Scientific Outlook for a post-factual world. Project Syndicate. The World's Opinion Page. https://www.project-syndicate.org/commentary/science-uncertaintypost-factual-world-by-helga-nowotny-2016-11

PolitiFact (n.d.). http://www.politifact.com/

Ridgway, J. (2016). Statistics Education and the Data Revolution. International Statistics Review. DOI: 10.1111 insr. 12110

Ridgway J., Arnold, P., Moy, W., and Ridgway, R. (2016). Deriving Heuristics from Political Speeches for Understanding Statistics about Society. International Association for Teaching Statistics Round Table Conference, Berlin. July 19-22, 2016. https://iaseweb.org/documents/papers/rt2016/Ridgway.pdf

Ridgway, J. (2017). Inquiry into "Fake News": written evidence submitted to the Culture, Media and Sport Committee. http://data.parliament.uk/writtenevidence/committeeevidence.svc/evidencedocument/culturemedia-and-sport-committee/fake-news/written/48179.html

Scott Jones, J. \& Goldring, J. E. (2014). Skills in mathematics and statistics in sociology and tackling transition. The Higher Education Academy STEM Project Series. York, England: Higher Education Academy. Cited in Scott Jones and Goldring (2017).

Scott Jones, J. \& Goldring, J. E. (2017). Statistics Education Research Journal, 16(1).

Stats and Stories (n.d.) http://www.cas.miamioh.edu/statsandstories/index.html

Thouless, R.H. (1930). Straight and Crooked Thinking. London, England: Hodder Education.

Trump, D. (2017). Video recording. channel4.com/news/alternative-facts-the-new-order-of-thewhite-house. 
UK Statistics Authority (n.d.). https://www.statisticsauthority.gov.uk/

Watson, J.M. (2006). Statistical literacy at school: Growth and goals. Mahwah, NJ: Lawrence Erlbaum. 